\title{
Crenças docentes e implicações para o processo de ensino-aprendizagem
}

\author{
Mirella Lopez Martini Fernandes Paiva \\ Zilda Aparecida Pereira Del Prette
}

\begin{abstract}
Resumo
O objetivo deste estudo foi identificar crenças educacionais de professores do Ensino Fundamental e examinar seu padrão facilitador ou dificultador da aprendizagem dos alunos. Coletados por meio de um questionário e analisados quantitativa e qualitativamente, os resultados indicaram que os professores facilitadores diferenciaram-se dos dificultadores basicamente em: maior concordância com a noção de que as relações interpessoais e o desenvolvimento socioemocional e intelectual dos alunos estão associados; maior valorização das habilidades sociais como componente do desenvolvimento socioemocional e da aprendizagem acadêmica dos alunos; maior quantidade e diversidade de explicações, analisadas em termos de atribuições de causalidade para o sucesso e fracasso escolar dos alunos. Discutem-se as implicações dessas crenças sobre as ações docentes e sobre o desenvolvimento e a aprendizagem dos alunos.
\end{abstract}

Palavras-chave: Desempenho acadêmico, interação professor-aluno, expectativa do professor.

\section{Teacher's beliefs and implications to the teaching-learning process}

\begin{abstract}
This study aimed to identify elementary school teacher's educational beliefs and to classify teachers according to patterns which facilitate or hinder their students' academic achievement. Data were collected by applying a questionnaire. This was analyzed within their qualitative and quantitative dimensions. Teachers whose beliefs potentially facilitate students' learning differed from the other group basically because they: agreed or strongly agreed with the idea of the relations among the students' interpersonal achievement, socio-emotional development and intellectual improvement; valued social skills as an important component of the students' socio-emotional development and academic achievement and pointed to a larger number of causal attributions to explain students' academic achievement. Implications of teacher's beliefs in their actions and relationships with student's development and learning were discussed.
\end{abstract}

Keywords: Academic achievement, teacher-stundent interaction, teacher expectations.

\section{Creencias docentes e implicaciones para el proceso de enseñanza-aprendizaje}

\begin{abstract}
Resumen
El objetivo de este estudio fue identificar creencias educativas de la enseñanza primaria y examinar su estándar facilitador o dificultador del aprendizaje de los alumnos. Recogidos por medio de un cuestionario y analizados cuantitativa y cualitativamente, los resultados indicaron que lo profesores facilitadores se diferencian de los dificultadores básicamente en: mayor concordancia con la noción de que las relaciones interpersonales y el desarrollo socio-emocional e intelectual de los alumnos están asociados; mayor valoración de las habilidades sociales como componente del desarrollo socio-emocional y del aprendizaje académico de los alumnos; mayor cantidad y diversidad de explicaciones, analizadas en términos de atribución de causalidad para el éxito o fracaso escolar de los alumnos. Son discutidas las implicaciones de estas creencias sobre las acciones docentes y sobre el desarrollo y aprendizaje de los alumnos.
\end{abstract}

Palabras-clave: Desempeño académico, interacción profesor- alumno, expectativas del profesor. 


\section{Introdução}

As crenças educacionais são ideias e convicções a respeito de temas relacionados à Educação que se revelam, conscientemente ou não, nas ações dos professores (Raymond \& Santos, 1995). Essas crenças influenciam o processo de ensino-aprendizagem ao mediarem as decisões pedagógicas e as interações que os professores estabelecem com seus alunos, funcionando como um filtro que os leva a interpretar, a valorizar e a reagir de diferentes formas diante dos progressos e dificuldades dos seus alunos, podendo, inclusive, induzir o comportamento real destes alunos em direção às suas expectativas (Pajares, 1992).

A esse respeito, em uma investigação sobre crenças docentes, Zohar, Degani e Vaaknin (2001) constataram que a maior parte dos professores investigados entendia que os alunos de baixo desempenho acadêmico não eram capazes de se envolver em atividades de aprendizagem que exigissem reflexão e raciocínio mais complexos e que se beneficiariam somente de aulas do tipo "transmissão de informações". Entretanto, essas crenças docentes contrapõem-se às evidências de que alunos de baixo desempenho acadêmico podem, de fato, obter consideráveis avanços em programas educacionais com métodos que requerem processamento cognitivo mais complexo. Resultados semelhantes foram encontrados em outros estudos, conforme revisão da literatura feita por Raudenbush, Rowan e Cheong (1993).

Embora literatura internacional venha demonstrando a influência das crenças educacionais sobre as ações dos professores em sala de aula e sobre a aprendizagem dos alunos nos últimos anos (Berry, 2006; Brighton, 2003; Calderhead, 1996; Errington, 2004; Warfield, Wood, \& Lehman, 2005), alguns autores alertam para a relevância e a consequente necessidade de intensificação desses estudos no Brasil (Martini, 2003; Melchiori, Alves, Souza, \& Bugliani, 2007; Sadalla, Saretta, \& Escher 2002).

No Brasil, as pesquisas sobre este tópico têm chegado a resultados semelhantes detectando, principalmente, a relação entre o fracasso escolar e a baixa expectativa do professor quanto ao desempenho acadêmico de seus alunos, especialmente quando estes são provenientes de classes sociais mais desfavorecidas. Em uma revisão dos estudos sobre atribuições de causalidade de professores para o desempenho acadêmico dos seus alunos, Martini e Boruchovitch (2004) identificaram que os professores tendem a atribuir o fracasso escolar predominantemente ao próprio aluno e à sua família e a esperar pouco sucesso de seus alunos, expressando uma compreensão do fracasso como decorrente de causas estáveis. Essas crenças estavam associadas a uma baixa expectativa de sucesso e alta de fracasso.

O que se percebe, portanto, é que dependendo da forma como se configuram, as crenças educacionais dos professores podem representar condições reconhecidamente dificultadoras da aprendizagem dos alunos como, por exemplo, acreditar que o aluno não é capaz de aprender e/ ou ter baixas expectativas quanto ao desempenho escolar do mesmo. Evidentemente, crenças opostas às acima seriam potencialmente facilitadoras do desempenho escolar dos alunos (Martini, 2003).

Com base nessas considerações, este estudo teve como objetivos: (a) caracterizar, empiricamente, um conjunto das crenças educacionais (sobre os processos de desenvolvimento, aprendizagem e o desempenho acadêmico dos alunos, bem como sobre as ações docentes em sala de aula) de uma amostra de professores do Ensino Fundamental; (b) analisar as características do padrão de crenças dos professores identificados como predominantemente dificultadores do desempenho escolar dos alunos e dos predominantemente facilitadores.

\section{Método}

\section{Participantes}

Fizeram parte deste estudo 33 professoras, com idade média de 35 anos, de $3^{\text {as }}$ séries do ensino fundamental de nove escolas da rede pública de uma cidade do interior de São Paulo/BR, escolhidas segundo o critério de aceitação para participação no estudo. Estas escolas representavam satisfatoriamente o conjunto das escolas públicas da cidade em termos de localização central e periférica.

\section{Instrumento}

Os dados foram obtidos por meio do Questionário de Avaliação de Crenças do Professor (QAC-P), um instrumento de autorrelato construído com base na literatura da área (A. Del Prette \& Z. A. P. Del Prette, 2003; Boruchovitch \& Martini, 2005). O QAC-P é composto por questões abertas e fechadas, conforme descritas abaixo.

Questão 1. avalia, em uma escala de zero a quatro, a concordância sobre duas afirmativas: (a) a qualidade dos relacionamentos interpessoais de uma criança afeta o seu desenvolvimento intelectual e (b) a qualidade dos relacionamentos interpessoais de uma criança afeta o seu desenvolvimento socioemocional.

Questão 2. avalia a importância, em uma escala de zero a dez, de: (a) 34 itens de habilidades sociais para o desenvolvimento socioemocional dos alunos e (b) 16 itens para a aprendizagem acadêmica (selecionados, por juízes, como os mais pertinentes, dentre os 34 itens, à aprendizagem acadêmica dos alunos). Esses itens compõem as diferentes classes de habilidades sociais, propostas por A. Del Prette e Z. A. P. Del Prette (2001): Comunicação, Civilidade, Assertivas de enfrentamento: direito e cidadania, Empáticas, Trabalho e Expressão de sentimentos.

Questão 3. avalia a importância, em uma escala de zero a dez, de 40 itens de habilidades sociais educativas. Essas habilidades compõem as classes mais gerais propostas por A. Del Prette e Z. A. P. Del Prette (2001): (a) apresentação das atividades, (b) transmissão e avaliação dos conteúdos, (c) promoção do desempenho socialmente habilidoso e (d) mediações de interações educativas entre os alunos. 
Tabela 1. Valor mínimo e máximo, mediana e grau de concordância das professoras com afirmativas que associavam relações interpessoais, desenvolvimento socioemocional e desenvolvimento intelectual.

\begin{tabular}{|c|c|c|c|c|}
\hline Relações & Mínimo-máximo & Mediana & Wilcoxon & Correlação \\
\hline $\begin{array}{c}\text { Relações Interpessoais e Desenvolvimento } \\
\text { Socioemocional }\end{array}$ & 0 a 4 & 3.00 & \multirow{2}{*}{$-2.165^{\star}$} & \multirow{2}{*}{$.840^{* *}$} \\
\hline $\begin{array}{l}\text { Relações Interpessoais e Desenvolvimento } \\
\text { Intelectual }\end{array}$ & 0 a 4 & 3.00 & & \\
\hline
\end{tabular}

Questão 4. avalia a quantidade ( $N$ total) e a qualidade (em uma escala de zero a quatro) das atribuições de causalidade de professores para situações de sucesso e fracasso escolar dos alunos. Nessa questão, são apresentadas aos professores quatro situações do cotidiano escolar. Os professores são, então, solicitados a imaginar que essas histórias são referentes a eles mesmos e seus alunos e, em seguida, a avaliar as possíveis causas responsáveis pelos desempenhos bem ou mal sucedidos dos seus alunos, em quatro situações descritas a seguir:

Situação 1. O professor passa para sua classe uma lição e constata que alguns foram bem sucedidos, devendo responder: (a) por que alguns alunos foram bem sucedidos e (b) por que alguns alunos foram mal sucedidos na realização da tarefa.

Situação 2. Ao corrigir as provas dos alunos, o professor constata diferentes desempenhos, devendo responder: por que alguns alunos que frequentemente apresentam alto, médio e baixo desempenho escolar apresentaram: (a) notas boas e (b) notas ruins na prova.

Situação 3. Ao final da aula, o professor percebe que a maioria dos alunos entendeu a matéria dada, devendo responder por que considera que a maioria desses alunos alcançou esse resultado.

Situação 4. Ao final da aula, o professor percebe que a maioria dos alunos não entendeu a matéria dada, devendo responder por que considera que a maioria desses alunos alcançou esse resultado.

Questão 5. avalia a intensidade da concordância do professor, em uma escala de zero a quatro, acerca de afirmações sobre fatores do processo de ensinoaprendizagem.

\section{Procedimentos de Coleta de Dados}

A aplicação do questionário foi coletiva, com duração em torno de 50 minutos. Assegurou-se o sigilo e o anonimato às professoras, que também assinaram um termo de consentimento, concordando com a participação na pesquisa.

\section{Tratamento dos Dados}

As pontuações obtidas no QAC-P, em cada uma das questões, foram estatisticamente normalizadas, de modo a tornar equivalente a contribuição de cada uma das questões na pontuação total. Os dados foram, então, tratados por estatística descritiva (percentil, mediana, porcentagem) e inferencial (Wilcoxon e Correlação de Spearman).

As respostas às questões abertas sobre as atribuições de causalidade foram objeto de análise de conteúdo e, então, classificadas nas categorias de um sistema de atribuições de causalidade, elaborado a partir da literatura da área (Weiner, 1985), porém aberto para a inclusão de novas categorias. A pontuação da quantidade de atribuições foi tomada como um indicador da capacidade da professora discriminar a multiplicidade de elementos do processo de ensino-aprendizagem e a de qualidade (avaliada em uma escala de zero a quatro) foi tomada como indicador do caráter dificultador (pontuação menor) ou facilitador (pontuação maior) das crenças sobre o desempenho acadêmico do aluno.

A pontuação total no QAC-P serviu de base para uma classificação das professoras em percentis, compondose dois grupos contrastantes: as professoras situadas no extremo superior da pontuação (crenças predominantemente facilitadoras da aprendizagem dos alunos) e as situadas no extremo inferior (predominantemente dificultadoras).

\section{Resultados}

\section{Análise do padrão geral de crenças das professoras da amostra}

A Tabela 1 apresenta os índices de concordância das professoras com afirmativas sobre a relação entre o desenvolvimento socioemocional, intelectual e interpessoal dos alunos. Verifica-se alta concordância das professoras com afirmações que associavam as relações interpessoais ao desenvolvimento socioemocional $(M=3.00)$ e intelectual $(M=3.00)$, com diferença significativa entre as pontuações dos dois conjuntos ( $\mathrm{s} 0.05$ ): as professoras concordam mais com a influência das relações interpessoais sobre 
Tabela 2. Dados descritivos (mediana, valores mínimos e máximos) e inferenciais (Wilcoxon e Correlação de Spearman) sobre as atribuições das professores com relação à importância das classes de habilidades sociais para o desenvolvimento socioemocional (DSE) e no desempenho acadêmico (DA) dos alunos.

\begin{tabular}{|c|c|c|c|c|}
\hline \multirow[t]{2}{*}{ CLASSES DE HABILIDADES SOCIAIS } & \multicolumn{2}{|c|}{$\begin{array}{c}\text { Mediana } \\
\text { (mínimo - máximo) }\end{array}$} & \multirow{2}{*}{ Wilcoxon } & \multirow[t]{2}{*}{ Correlação } \\
\hline & DSE & DA & & \\
\hline Habilidades Sociais de Comunicação & $\begin{array}{c}8.42 \\
(5.43-10.00)\end{array}$ & $\begin{array}{c}9.50 \\
(5.50-10.00)\end{array}$ & $-4.185^{\star *}$ & $.640^{\star *}$ \\
\hline Habilidades Sociais de Civilidade & $\begin{array}{c}9.50 \\
(6.25-10.00)\end{array}$ & $\begin{array}{c}9.66 \\
(5.67-10.00)\end{array}$ & -1.044 & $.730^{\star *}$ \\
\hline $\begin{array}{l}\text { Habilidades Sociais Assertivas de } \\
\text { Enfrentamento: Direito e Cidadania }\end{array}$ & $\begin{array}{c}8.16 \\
(4.42-10.00)\end{array}$ & $\begin{array}{c}8.75 \\
(6.75-10.00)\end{array}$ & $-2.068^{*}$ & $.578^{* *}$ \\
\hline Habilidades Sociais Empáticas & $\begin{array}{c}9.00 \\
(2.25-10.00)\end{array}$ & $\begin{array}{c}10.00 \\
(5.00-10.00)\end{array}$ & -.530 & .332 \\
\hline Habilidades Sociais de Trabalho & $\begin{array}{c}8.71 \\
(5.00-10.00)\end{array}$ & $\begin{array}{c}9.25 \\
(7.25-10.00)\end{array}$ & $-3.354^{* *}$ & $716^{* *}$ \\
\hline $\begin{array}{l}\text { Habilidades Sociais de Expressão de } \\
\text { Sentimentos Positivos }\end{array}$ & $\begin{array}{c}10.00 \\
(5.00-10.00)\end{array}$ & - & - & - \\
\hline TOTAL & $\begin{array}{c}8.61 \\
(6.00-10.00)\end{array}$ & $\begin{array}{c}9.18 \\
(6.63-10.00)\end{array}$ & $-4.180^{\star *}$ & $.828^{* *}$ \\
\hline
\end{tabular}

Fonte: Elaboração dos autores

${ }^{*} \mathrm{p} \leq 0.05 ;{ }^{* *} \mathrm{p} \leq 0.001$

o desenvolvimento socioemocional do que sobre o desenvolvimento intelectual dos alunos.

A Tabela 2 apresenta os dados descritivos da importância atribuída pelas professoras às classes de habilidades sociais para o desenvolvimento socioemocional e a aprendizagem acadêmica dos alunos. As professoras atribuíram alta importância para o repertório de habilidades sociais enquanto possível fator tanto do desenvolvimento socioemocional dos alunos como do desempenho acadêmico ( $M=8.61$ e $M=9.18$ respectivamente). A mediana de todos os itens foi acima de oito (em escala de zero a dez) com significativos índices de correlação positiva $(p \leq 0.001)$ para todas as classes (exceto para a classe de Habilidades Sociais Empáticas), mostrando que, em geral, os itens valorizados para a aprendizagem também foram valorizados para o desenvolvimento socioemocional. Ainda assim, as Habilidades Sociais de Comunicação e as Assertivas de Enfrentamento foram mais valorizadas para a aprendizagem acadêmica $(M=9.50 ; p \leq 0.001$ e $M=8.75$; $\mathrm{p} \leq 0.05$ respectivamente) do que para o desenvolvimento socioemocional dos alunos.

A Tabela 3 apresenta os dados descritivos dos itens que compõem cada uma das classes de habilidades sociais, com relação à importância a elas atribuída pelas professoras enquanto fator do desenvolvimento socioemocional e da aprendizagem acadêmica. Das 16 habilidades selecionadas como relevantes para a aprendizagem acadêmica, somente quatro se destacaram: as habilidades de Responder perguntas $(M=10.00 ; p \leq 0.01)$ e Corrigir informação que considera errada $(M=10.00 ; p \leq 0.05)$ foram mais valorizadas para a aprendizagem acadêmica e as habilidades de Aceitar recusa ou discordância $(M=8.00 ; p \leq 0.05)$ e Elogiar, gratificar outras pessoas $(M=10.00 ; p \leq 0.01)$ foram consideradas mais importantes para o desenvolvimento socioemocional dos alunos.

Quando se comparou, duas a duas, as classes mais gerais de habilidades sociais educativas (Tabela 4), verificouse que as professoras avaliaram todas como facilitadoras da aprendizagem dos alunos, porém as habilidades de mediação de interações sociais educativas entre os alunos, tão relevantes para a construção social do conhecimento e aprendizagem, sob as perspectivas construtivista e sociointeracionista (A. Del Prette \& Z. A. P. Del Prette, 2001) foram menos valorizada em todas as comparações efetuadas.

As professoras avaliaram o conjunto das habilidades sociais educativas como ações potencialmente promotoras da aprendizagem dos alunos (Mediana > 9.0, em escala de zero a 10). Entretanto, alguns itens específicos foram menos valorizados, tais como: Negociar decisões sobre atividades com seus alunos $(M=9.00)$, Usar estratégias não punitivas para interromper ações inadequadas dos alunos $(M=9.00)$, 
Tabela 3. Diferenças e semelhanças (Wilcoxon e Correlação de Spearman) com relação ao peso atribuído pelas professoras aos itens das classes de habilidades sociais no desenvolvimento socioemocional (DSE) e no desempenho acadêmico (DA).

\begin{tabular}{|c|c|c|c|c|}
\hline \multirow{2}{*}{\multicolumn{2}{|c|}{ CLASSES E ITENS DE HABILIDADES SOCIAIS }} & \multicolumn{2}{|c|}{ Mediana (min-max) } & \multirow{2}{*}{ Wilcoxon } \\
\hline & & DSE & DA & \\
\hline \multirow{7}{*}{$\begin{array}{l}\text { Comuni- } \\
\text { cação }\end{array}$} & Fazer perguntas. & $10(0-10)$ & $10(0-10)$ & -.900 \\
\hline & Responder perguntas. & $9(0-10)$ & $10(6-10)$ & $-2.549^{* *}$ \\
\hline & Elogiar, gratificar outras pessoas. & $10(5-10)$ & $10(2-10)$ & $-2.558^{\star *}$ \\
\hline & Iniciar contato e conversação com outras pessoas. & $9(5-10)$ & - & \\
\hline & Manter conversação olhando nos olhos do outro. & $10(6-10)$ & $10(2-10)$ & -.351 \\
\hline & Interromper conversação com outras pessoas & $4(0-10)$ & - & - \\
\hline & Falar sobre si mesmo. & $9(0-10)$ & - & - \\
\hline \multirow{4}{*}{ Civilidade } & Cumprimentar, dizer por favor, obrigado. & $10(8-10)$ & - & - \\
\hline & Agradecer elogios recebidos. & $10(3-10)$ & $10(2-10)$ & -2.200 \\
\hline & Ouvir atentamente o outro. & $10(6-10)$ & $10(6-10)$ & -1.496 \\
\hline & Pedir favor ou ajuda. & $9(5-10)$ & $10(1-10)$ & -1.364 \\
\hline \multirow{12}{*}{$\begin{array}{l}\text { Assertivas, } \\
\text { Direito e } \\
\text { Cidadania }\end{array}$} & Discordar & $9(5-10)$ & $9(4-10)$ & -.860 \\
\hline & Dar opinião/sugestão. & $10(5-10)$ & $10(8-10)$ & -1.119 \\
\hline & Recusar pedidos abusivos de colegas. & $10(0-10)$ & - & - \\
\hline & Aceitar recusa ou discordância. & $8(4-10)$ & $7(3-10)$ & $-1.959^{*}$ \\
\hline & Desculpar-se, admitir erro. & $10(7-10)$ & - & - \\
\hline & $\begin{array}{l}\text { Defender-se verbalmente de acusações ou críticas } \\
\text { injustas. }\end{array}$ & $9(5-10)$ & - & - \\
\hline & Aceitar críticas justas & $9(5-10)$ & $9(2-10)$ & -.950 \\
\hline & $\begin{array}{l}\text { Expressar sentimentos de raiva ou desagrado de forma } \\
\text { adequada. }\end{array}$ & $8(0.10)$ & - & - \\
\hline & Pedir mudança de comportamento do outro. & $8(0-10)$ & - & - \\
\hline & $\begin{array}{l}\text { Resistir à pressão de colegas que querem lhe impor o } \\
\text { que fazer. }\end{array}$ & $9(0-10)$ & - & - \\
\hline & Aceitar gozações de colegas. & $7(0-10)$ & - & - \\
\hline & Defender colega de acusação injusta. & $9(3-10)$ & - & - \\
\hline \multirow{2}{*}{ Empáticas } & Acalmar/consolar colega. & $9(3-10)$ & - & - \\
\hline & Oferecer ajuda. & $10(2-10)$ & $10(5-10)$ & -.284 \\
\hline \multirow{7}{*}{ Trabalho } & Convencer colegas a fazerem algo. & $8(3-10)$ & - & - \\
\hline & Cooperar, compartilhar. & $10(5-10)$ & $10(5-10)$ & -.085 \\
\hline & Organizar atividades de grupo. & $9(7-10)$ & $9(5-10)$ & -.072 \\
\hline & Corrigir informação que considera errada. & $9(0-10)$ & $10(0-10)$ & $-2.106^{*}$ \\
\hline & Convidar colegas para atividades. & $9(5-10)$ & $10(5-10)$ & -.450 \\
\hline & Negociar decisões. & $9(0-10)$ & - & - \\
\hline & Mediar conflitos entre colegas. & $9(0-10)$ & - & - \\
\hline \multirow{2}{*}{$\begin{array}{l}\text { Expressão } \\
\text { de Sentim. } \\
\text { Positivo }\end{array}$} & Alegrar-se por algo bom que acontece a colega. & $10(0-10)$ & - & - \\
\hline & $\begin{array}{l}\text { Expressar sentimentos de carinho, satisfação ou } \\
\text { ternura }\end{array}$ & $10(0-10)$ & - & - \\
\hline
\end{tabular}


Tabela 4. Dados descritivos e inferenciais sobre a avaliação, pelas professoras, das quatro classes de Habilidades Sociais Educativas.

\begin{tabular}{|c|c|c|}
\hline $\begin{array}{c}\text { CLASSES DE HABILIDADES SOCIAIS EDUCATIVAS } \\
\text { COMPARADAS ENTRE SI }\end{array}$ & $\begin{array}{c}\text { Mediana } \\
\text { (min.-max.) }\end{array}$ & Wilcoxon \\
\hline $\begin{array}{l}\text { 1. Habilidades de apresentação das atividades } \\
\text { 4. Habilidades de mediação de interações sociais educativas entre os } \\
\text { alunos }\end{array}$ & $\begin{array}{l}9.57(6.43-10.0) \\
8.60(5.0-10.0)\end{array}$ & $-4.444^{*}$ \\
\hline $\begin{array}{l}\text { 2. Habilidades de transmissão e avaliação dos conteúdos } \\
\text { 4. Habilidades de mediação de interações sociais educativas entre os } \\
\text { alunos }\end{array}$ & $\begin{array}{l}9.46(7.77-10.0) \\
8.60(5.0-10.0)\end{array}$ & $-4.284^{*}$ \\
\hline $\begin{array}{l}\text { 3. Habilidades de promoção do desempenho socialmente habilidoso } \\
\text { 4. Habilidades de mediação de interações sociais educativas entre os } \\
\text { alunos }\end{array}$ & $\begin{array}{l}9.60(7.80-10.0) \\
8.60(5.0-10.0)\end{array}$ & $-4.363^{*}$ \\
\hline
\end{tabular}

Pedir que um aluno refaça uma tarefa apenas parcialmente correta $(M=8.00)$, Expressar sentimentos de raiva ou desagrado de forma adequada $(M=8.00)$ e também outros que envolvem interação entre os alunos como, por exemplo, Fazer pergunta dirigida a um aluno específico ao invés de dirigida à classe toda $(M=8.00)$, e Direcionar a pergunta de um aluno para que um colega a responda $(M=8.00)$.

Quanto às explicações das professoras para o sucesso escolar dos alunos (Tabela 5), foi possível verificar que a atribuição de causalidade predominante na situação em que todos os alunos fizeram uma boa lição foi a Capacidade do aluno $(75,76 \%)$ e também nas situações em que os alunos de alto $(75,76 \%)$ e médio $(48,48 \%)$ desempenho tiraram boas notas na prova. Porém, nos casos dos alunos de baixo desempenho escolar, a explicação predominante foi o Esforço (51,52\%). Na situação em que os alunos entenderam bem uma aula, as professoras atribuíram a si mesmas a maior parte do sucesso, destacando-se, aqui, a categoria Ajuda do professor (81,82\%).

A Tabela 6 descreve que, em relação às situações de fracasso escolar (em que alunos fazem mal uma lição e em que os alunos de baixo desempenho escolar tiram uma nota baixa), a causa predominantemente atribuída pelas professoras nas situações foi a Falta de Capacidade do aluno $(81,82 \%$ e $60,61 \%)$. As notas baixas dos alunos de alto desempenho escolar foram atribuídas às Características Emocionais (57,58\%) enquanto que as dos alunos de médio desempenho, à Falta de esforço (54,55\%). Na situação em que os alunos não entenderam bem uma aula, as professoras também atribuíram a si mesmas o fracasso do aluno (Falta Ajuda do professor $60,61 \%)$, embora em proporção menor do que no caso de sucesso $(39,39 \%)$.
No que se refere à porcentagem de professoras que concordaram com as afirmações apresentadas na Questão 5 (Tabela 7), verificou-se que os maiores índices de concordância foram para as afirmações referentes à Ajuda do professor para o sucesso do aluno (87.88\%, 54.55\%, $100 \%$ e $100 \%$ ) e os menores índices de concordância foram para as afirmações que explicam o fracasso pela Falta de capacidade $(0 \%, 12,12 \%$ e $15,15 \%)$ e Sorte dos alunos $(3,03 \%)$, e para o papel do Conteúdo da tarefa escolar como elemento facilitador da aprendizagem do aluno (3.03\%). Apesar das professoras se autovalorizarem como fator importante do sucesso do aluno, parecem não concordar que a falta dessa ajuda possa dificultar essa aprendizagem $(18,18 \%)$.

\section{Classificação das professoras conforme seu padrão de crenças.}

A distribuição das professoras, conforme a pontuação no QAC-P, normalizada, variou de 27 a 47 (Mediana = 39). Com base nessa distribuição, foi possível identificar as oito professoras com pontuações abaixo do primeiro quartil (menores que 33,50), ou seja, aquelas que apresentaram um padrão de crenças predominantemente dificultador da aprendizagem do aluno e as oito professoras com pontuações acima do terceiro quartil (maiores que 40,00 ) no QAC-P, isto é, que apresentaram crenças predominantemente facilitadoras da aprendizagem dos alunos. As demais professoras foram consideradas com padrão misto de crenças dificultadoras e facilitadoras.

As professoras facilitadoras, comparadas às dificultadoras, apresentaram um padrão mais favorável ao 
Tabela 5. Porcentagens de professoras nas diferentes categorias de atribuições de causalidade para sucesso escolar dos alunos nas cinco situações apresentadas (Questão 4 do QAC-P)

\begin{tabular}{llllll}
\hline \multirow{2}{*}{$\begin{array}{c}\text { ATRIBUIÇÕES DE } \\
\text { CAUSALIDADE }\end{array}$} & \multicolumn{4}{c}{ HISTÓRIAS DE SUCESSO ESCOLAR DOS ALUNOS } \\
\cline { 2 - 5 } & $\begin{array}{c}\text { Fizeram bem } \\
\text { uma lição }\end{array}$ & \multicolumn{2}{c}{ Obtiveram boa nota na prova } & \multirow{2}{*}{$\begin{array}{c}\text { Entenderam bem } \\
\text { uma aula }\end{array}$} \\
\cline { 2 - 5 } Capacidade do aluno & 75,76 & 75,76 & 48,48 & 33,33 & 12,12 \\
\hline Esforço do aluno & 48,48 & 51,52 & 39,39 & 51,52 & 42,42 \\
\hline Facilidade da tarefa & 0,0 & 0,0 & 6,06 & 9,80 & 9,09 \\
\hline Ajuda do professor & 9,09 & 6,06 & 21,21 & 27,27 & 81,82 \\
\hline $\begin{array}{l}\text { Características emocionais do } \\
\text { aluno }\end{array}$ & 6,06 & 3,03 & 12,12 & 21,21 & 3,03 \\
\hline $\begin{array}{l}\text { Características familiares do } \\
\text { aluno }\end{array}$ & 6,06 & 27,27 & 3,03 & 6,06 & 3,03 \\
\hline
\end{tabular}

Fonte: Elaboração dos autores

Tabela 6. Porcentagens de professoras nas diferentes categorias de atribuições de causalidade para fracasso escolar dos alunos nas cinco situações apresentadas (Questão 4 do QAC-P)

\begin{tabular}{|c|c|c|c|c|c|}
\hline \multirow{3}{*}{$\begin{array}{l}\text { ATRIBUIÇÕES DE } \\
\text { CAUSALIDADE }\end{array}$} & \multicolumn{5}{|c|}{ HISTÓRIAS DE FRACASSO ESCOLAR DOS ALUNOS } \\
\hline & \multirow{2}{*}{$\begin{array}{l}\text { Fizeram mal } \\
\text { uma lição }\end{array}$} & \multicolumn{3}{|c|}{ Tiraram nota baixa em uma prova } & \multirow{2}{*}{$\begin{array}{l}\text { Não } \\
\text { entenderam } \\
\text { uma aula }\end{array}$} \\
\hline & & Alto & Médio & Baixo & \\
\hline Falta de capacidade do aluno & 81,82 & 48,48 & 39,39 & 60,61 & 18,18 \\
\hline Falta de esforço do aluno & 57,52 & 54,55 & 54,55 & 39,39 & 54,55 \\
\hline Dificuldade da tarefa & 0,0 & 0,0 & 12,12 & 0,0 & 36,36 \\
\hline Falta de ajuda do professor & 6,06 & 15,15 & 24,24 & 15,15 & 60,61 \\
\hline $\begin{array}{l}\text { Características emocionais do } \\
\text { aluno }\end{array}$ & 6,06 & 57,58 & 24,24 & 18,18 & 15,15 \\
\hline $\begin{array}{l}\text { Características familiares do } \\
\text { aluno }\end{array}$ & 6,06 & 15,15 & 18,18 & 9,09 & 0,0 \\
\hline
\end{tabular}

Fonte: Elaboração dos autores

desenvolvimento e à aprendizagem dos alunos bem como à qualidade da prática docente. As primeiras concordaram Muito ou Totalmente com a afirmação de que as relações interpessoais e o desenvolvimento socioemocional e intelectual dos alunos estão associados, enquanto as segundas concordaram Pouco ou Nada com esta afirmação. Constatou-se uma alta valorização do repertório de habilidades sociais como fator do desenvolvimento socioemocional e da aprendizagem acadêmica dos alunos pelos dois grupos de professoras, porém esta valorização foi ainda maior pelas professoras facilitadoras do que pelas professoras dificultadoras. As habilidades sociais educativas foram avaliadas muito positivamente pelos dois grupos, porém menos intensamente pelas professoras com crenças dificultadoras.

Os dois grupos de professoras não se diferenciaram em relação à qualidade das atribuições de causalidade e explicaram o sucesso e fracasso escolar dos alunos sobretudo pelas atribuições de Capacidade e Esforço. Entretanto, as respostas das professoras facilitadoras às diferentes situações do QAC-P apresentaram uma quantidade maior de atribuições de causalidade como explicações do sucesso 
Tabela 7. Percentagem de concordância das professoras acerca das crenças educacionais (Questão 5 do QAC-P)

\begin{tabular}{|c|c|c|}
\hline CRENÇAS EDUCACIONAIS & ITENS & $\begin{array}{l}\text { Concordância } \\
(\%)\end{array}$ \\
\hline $\begin{array}{l}\text { Características familiares do } \\
\text { aluno em situações de fracasso. }\end{array}$ & $\begin{array}{l}\text { Quando o aluno não consegue aprender é porque } \\
\text { os pais não colaboram com o estudo dos filhos em } \\
\text { casa. }\end{array}$ & 39,39 \\
\hline Facilidade da tarefa & $\begin{array}{l}\text { Quando grande parte dos meus alunos tira boas } \\
\text { notas é porque a matéria foi fácil }\end{array}$ & 3,03 \\
\hline Falta de sorte do aluno & $\begin{array}{l}\text { Quando um aluno estuda a matéria, mas tira uma } \\
\text { nota ruim na prova, é porque não teve sorte. }\end{array}$ & 3,03 \\
\hline \multirow[t]{3}{*}{ Falta de capacidade do aluno } & $\begin{array}{l}\text { Se um aluno não aprende a explicação da matéria é } \\
\text { porque não tem capacidade }\end{array}$ & 0,00 \\
\hline & $\begin{array}{l}\text { Para adequar o ensino às crianças mais pobres } \\
\text { preciso exigir menos delas em sala de aula. }\end{array}$ & 12,12 \\
\hline & $\begin{array}{l}\text { A inteligência das crianças é praticamente constante } \\
\text { e, portanto, elas não ficam mais inteligentes com o } \\
\text { tempo }\end{array}$ & 15,15 \\
\hline Falta de ajuda do professor & $\begin{array}{l}\text { Se um aluno não aprendeu a explicação da matéria } \\
\text { é porque o professor não soube explicar da melhor } \\
\text { forma }\end{array}$ & 18,18 \\
\hline \multirow[t]{2}{*}{$\begin{array}{l}\text { Características emocionais do } \\
\text { aluno }\end{array}$} & $\begin{array}{l}\text { Mesmo que eu me esforce, não terei bons resultados } \\
\text { com aqueles alunos que apresentam problemas na } \\
\text { escola ou que estão desmotivados. }\end{array}$ & 27,27 \\
\hline & $\begin{array}{l}\text { Quando o aluno não é motivado por si só, o } \\
\text { professor pouco pode fazer por ele }\end{array}$ & 15,15 \\
\hline \multirow{4}{*}{ Ajuda do professor } & $\begin{array}{l}\text { Todo professor pode conseguir que seu aluno esteja } \\
\text { motivado e aprenda na escola, mesmo que a família } \\
\text { não coopere para isso. }\end{array}$ & 87,88 \\
\hline & $\begin{array}{l}\text { Embora o professor trabalhe em sala de aula com } \\
\text { cerca de } 40 \text { alunos, ele pode atender muito das } \\
\text { necessidades individuais destes alunos. }\end{array}$ & 54,55 \\
\hline & $\begin{array}{l}\text { A escola pode ajudar a promover o desenvolvimento } \\
\text { social e emocional dos alunos }\end{array}$ & 100,00 \\
\hline & $\begin{array}{l}\text { Muito da aprendizagem dos alunos depende do meu } \\
\text { aperfeiçoamento contínuo }\end{array}$ & 100,00 \\
\hline
\end{tabular}

Fonte: Elaboração dos autores

e fracasso escolar dos alunos, sugerindo maior capacidade de análise e discriminação dos componentes do processo de ensino-aprendizagem que as professoras dificultadoras.

\section{Discussão}

Os dados do QAC-P indicaram alta concordância das professoras com as afirmações de que as relações interpessoais e o desenvolvimento socioemocional e intelectual dos alunos estão associados, porém a diferença significativa entre esses dois eixos do desenvolvimento infantil mostrou que, para essas professoras, o desenvolvimento intelectual de uma criança não é tão fortemente influenciado pela qualidade dessas interações e pelo desenvolvimento socioemocional da criança. Esse resultado sugere que as professoras ainda não assimilaram totalmente a importância das interações sociais como um fator de desenvolvimento socioemocional e cognitivo (Cubero \& Luque, 2004). 
De modo geral, as professoras reconheceram as classes de habilidades sociais como fator de desempenho acadêmico e do desenvolvimento social e emocional dos alunos (exceto no que se refere à classe de Habilidades Sociais Empáticas) e apresentaram uma valorização ainda maior das Habilidades Sociais de Comunicação e Habilidades Sociais Assertivas de Enfrentamento para a aprendizagem acadêmica dos alunos do que para o seu desenvolvimento socioemocional. Possivelmente, os itens dessas duas classes retratam mais prontamente o padrão interativo usual de sala de aula destes professores, com participação ativa e motivação dos alunos nas atividades escolares. Outra explicação possível é o fato dessas duas classes terem sido menos valorizadas enquanto fatores do desenvolvimento socioemocional, revelando-se, aqui, certa lacuna de conhecimento sobre essa área na formação das professoras. De todo modo, esse resultado contradiz os de outro estudo sobre a importância das habilidades sociais na perspectiva de 140 professores (A .Del Prette \& Z. A. P. Del Prette, 2003), em que as habilidades assertivas e de enfrentamento foram as menos valorizadas. Esse contraste permite supor a amostra do presente estudo como diferenciada, pelo menos em relação a uma melhor compreensão sobre a importância das habilidades sociais para o desenvolvimento e a aprendizagem.

Embora tenham sido encontradas diferenças na comparação entre as avaliações das professoras sobre os dois conjuntos (socioemocional e acadêmico), os altos escores de ambos revelam o reconhecimento, pelas professoras, de requisitos indispensáveis na formação para a vida e para a cidadania. A aquisição desses requisitos inclui articulação entre desenvolvimento cognitivo, social e emocional dos alunos. Traduzir essas crenças em ações docentes que viabilizem a aprendizagem de habilidades sociais na escola torna-se um passo fundamental e um desafio ao trabalho do psicólogo escolar, principalmente quando se constata a correlação positiva dos déficits no repertório de habilidades sociais dos alunos com dificuldades de aprendizagem, comportamentos antissociais e uma variedade de transtornos psicológicos e desajustes psicossociais (A. Del Prette \& Z. A. P. Del Prette, 2003, 2006; Gresham, Lane, \& Mac Millan, 1999).

Considerando-se o subconjunto dos 16 itens de habilidades selecionadas como importantes para a aprendizagem acadêmica, em comparação com sua relevância para o desenvolvimento socioemocional, pôdese verificar que a maioria das habilidades foi valorizada para os dois contextos (acadêmico e socioemocional) com diferença significativa somente em quatro itens. As habilidades de Responder perguntas e Corrigir informação que considera errada, avaliadas pelas professoras como mais relevantes para a aprendizagem acadêmica, poderiam estar refletindo a preocupação destas com a participação ativa, motivação e interesse do aluno em sala de aula. Por outro lado, as habilidades de Aceitar recusa ou discordância e Elogiar, gratificar outras pessoas, menos valorizadas para a aprendizagem acadêmica, podem ter sido entendidas como mais pertinentes aos relacionamentos interpessoais extraescolares e, portanto, menos diretamente associadas ao trabalho docente e às interações sociais de sala de aula.

Ao lado das habilidades sociais específicas identificadas como importantes para a aprendizagem acadêmica, um bom repertório de habilidades sociais é, em geral, entendido como um facilitador acadêmico ("academic enabler", conforme Di Perna, Volpe, \& Elliott, 2001), mesmo quando a preocupação central é com o desenvolvimento socioemocional. Habilidades como Expressar sentimentos negativos adequadamente, Pedir mudança de comportamento, Negociar decisões, Lidar com críticas, entre outras, que precisam ser promovidas na escola, podem, ainda, constituir fator preventivo da indisciplina e de comportamentos violentos, que competem com os comportamentos requeridos na aprendizagem e participação em sala de aula (Gresham e cols., 1999).

Com relação às habilidades sociais educativas das professoras, foi possível verificar que a amostra geral e também os subgrupos de professoras facilitadoras e dificultadoras reconhecem-se como potencialmente promotoras da aprendizagem dos alunos, relacionando o desempenho destes com sua atuação profissional e, em particular, com seu desempenho na interação com o aluno. Muito embora os itens mais valorizados sugiram uma preocupação maior das professoras com interações voltadas para a manutenção do controle, da disciplina e da autoridade em sala de aula, em detrimento de condições educativas que ampliam a participação dos alunos na construção de conhecimento, esse resultado é altamente positivo, pois revela crenças positivas de autoeficácia docente (Goya, Bzuneck, \& Guimarães, 2008; Olaz, 2009).

As crenças de autoeficácia influenciam a motivação dos professores, contribuem para seu bem-estar pessoal no trabalho e para atitudes e comportamentos mais adaptados ao processo de ensino-aprendizagem. Professores com crenças favoráveis de autoeficácia demonstram maior compromisso com o ensino, adotam procedimentos mais eficazes para lidar com as dificuldades de aprendizagem dos alunos, tendem a introduzir práticas inovadoras, assumem uma postura mais democrática em classe, além de se mostrarem mais habilidosos ao lidarem com fatores acadêmicos estressantes (Goya e cols., 2008).

No ambiente de sala de aula, as demandas para habilidades sociais educativas são, de fato, ainda maiores quando o professor reconhece a importância das interações com e entre os alunos para a aprendizagem e, portanto, o seu papel na mediação dessas interações por meio de práticas pedagógicas alternativas ao padrão tradicional geralmente encontrado nas escolas (A. Del Prette \& Z. A. P. Del Prette, 2001). Os resultados deste estudo sugerem que pelo menos uma parte das professoras entendia o processo de ensino-aprendizagem para além da ótica do sucesso, da eficiência e dos resultados imediatos, na medida em que valorizavam as ações docentes voltadas tanto para os processos de aprendizagem como para o desenvolvimento socioemocional dos alunos. 
Esses dados são um tanto diferentes dos obtidos na análise de situações específicas de sucesso ou fracasso escolar, ainda que com resultados confirmando os dados da literatura. O sucesso e o fracasso no processo ensinoaprendizagem foram compreendidos pelo professor como primordialmente de responsabilidade dos alunos (Martini \& Boruchovitch, 2004; Neves \& Almeida, 1996;). Na maioria das situações avaliadas, as professoras não reconheceram seu papel fundamental como agentes e mediadoras do processo ensino-aprendizagem, contrariando, portanto, o discurso de valorização geral do próprio desempenho e de habilidades específicas requeridas nesse desempenho (Questão 3 do QAC-P, antes referida). Esse resultado sugere um "discurso" contraditório, ou, possivelmente, o efeito da metodologia de coleta de dados sobre suas crenças, requerendo, portanto, investigações adicionais. É possível que a expressão de algumas crenças mais generalizadas se mantenha quando a situação de avaliação é mais geral, mas que não se sustente quando se toma situações específicas para análise, nesse caso, induzindo mais diretamente a preocupação com a preservação do autoconceito no trabalho, o que tem sido verificado em outros estudos (Neves \& Almeida, 1996).

Nas situações de sucesso escolar, as professoras atribuíram o bom desempenho dos alunos basicamente à capacidade e ao esforço dos próprios alunos. Essas atribuições são altamente favoráveis ao sucesso escolar se os professores expressarem-nas em sua interação com os alunos, pois assim podem estimular o autoconceito positivo dos alunos, o sentimento de competência no processo de aprendizagem e a motivação para realização das atividades acadêmicas, contribuindo para um melhor desempenho escolar (Martini \& Z. A. P. Del Prette, 2002). Em contrapartida, as professoras atribuíram à falta de capacidade o fato dos alunos não fazerem bem uma lição e dos alunos de baixo desempenho escolar não tirarem boas notas. Essa atribuição teria um efeito oposto se expressa pelo professor aos alunos, pois poderia induzir-Ihes o ceticismo e a desmotivação quanto à própria competência acadêmica dos alunos, com implicações e desdobramentos em relação a problemas de comportamento e de aprendizagem (Martini \& Boruchovitch, 2004). Além disso, sinalizaria baixa disposição do professor em buscar estratégias alternativas de ensino e em assumir seu papel ativo e efetivo na aprendizagem do aluno.

\section{Considerações Finais}

O presente estudo caracterizou um conjunto de crenças docentes sobre o processo de ensino-aprendizagem e identificou padrões de crenças potencialmente facilitadores ou dificultadores do desenvolvimento e da aprendizagem dos alunos na escola. Mais especificamente, o conjunto de crenças investigado versou sobre três componentes: as habilidades sociais educativas das professoras, as habilidades sociais dos alunos e as atribuições de causalidade das professoras quanto ao sucesso e fracasso escolar. Esses três componentes estão fortemente associados à qualidade do desenvolvimento social, afetivo e cognitivo, à atuação profissional dos professores e às interações entre eles em sala de aula (Goya e cols., 2008; 2008; Martini, 2003; Olaz, 2009; Weiner, 2006).

Não obstante as reflexões que este estudo suscita, é importante reconhecer suas limitações, a começar pela baixa quantidade e diversidade da amostra de professores e pela falta de dados de observação direta em sala de aula, que permitiriam de fato caracterizar a importância das crenças sobre a atuação do professor, sobre a qualidade de sua interação com os alunos e, por essa via, sobre a aprendizagem e o rendimento desses alunos. Assim, um importante encaminhamento para novas pesquisas nessa área seria a verificação das relações entre as crenças educacionais das professoras e suas ações observáveis em sala de aula enquanto base para nortear programas de capacitação em maior escala.

Apesar das professoras facilitadoras revelarem, em seu discurso verbal, crenças altamente favoráveis ao desenvolvimento e à aprendizagem dos alunos e à sua atuação docente, como a concretização dessas crenças nem sempre se traduz em prática efetiva no cotidiano de sala de aula, identifica-se aqui um importante foco de intervenção para o psicólogo escolar. Conhecer tais crenças e identificar padrões presentes no cotidiano da escola representam um esforço inicial nessa direção e constituem importantes subsídios para se repensar a formação acadêmica e continuada do professor, com vistas a melhorar a qualidade da educação escolar. $\mathrm{Na}$ continuidade, entende-se que esse conhecimento pode e deve ser utilizado pelos psicólogos, especialmente os psicólogos escolares, como um ponto de partida ou de apoio para a assessoria direcionada ao sucesso escolar por meio da desconstrução de um discurso educacional que não o favorece, muitas vezes até o dificulta, e por meio da capacitação a professores para implementarem procedimentos coerentes com um ideário pedagógico mais favorável à superação do fracasso escolar.

\section{Referências}

Berry, R. A. W. (2006). Beyond strategies: teacher beliefs and writing instruction in two primary inclusion classroom. Journal of Learning Disabilities, 39(1), 11-24.

Boruchovitch, E., \& Martini, M. L. (2005). A construção de um instrumento para avaliação das atribuições de causalidade em contexto escolar. Anais do /I Congresso Brasileiro de Avaliação Psicológica (p. 18). Gramado, RS: Instituto Brasileiro de Avaliação Psicológica.

Brighton, C. M. (2003). The effects of middle school teachers' beliefs on classroom practices. Journal for the Education of the Gifted, 27(2-3), 177-206.

Calderhead, J. (1996). Teachers: beliefs and knowledge. In D. C. Berlinger \& R. C. Calfee (Eds.), Handbook of research on teaching (pp. 709-725). New York: McMillian.

Cubero, R., \& Luque, A. (2004). Desenvolvimento, educação e educação escolar: a teoria sociocultural do desenvolvimento e da aprendizagem. Em C. Coll, J. Palácios \& A. Marchesi (Eds.), Desenvolvimento Psicológico e Educação. Psicologia da Educação (pp. 94-106). Porto Alegre: Artes Médicas. 
Del Prette, A., \& Del Prette, Z. A. P. (2001). Psicologia das relações interpessoais: vivências para o trabalho em grupo. Petrópolis:Vozes.

Del Prette, A., \& Del Prette, Z. A. P. (2003). Aprendizagem socioemocional na escola e prevenção da violência: Questões conceituais e metodologia de intervenção. Em A. Del Prette \& Z. A. P. Del Prette (Eds.), Habilidades sociais, desenvolvimento e aprendizagem: Questões conceituais, avaliação e intervenção (pp. 83-127). Campinas, SP: Alínea.

Del Prette, A., \& Del Prette, Z. A. P. (2006). Adolescência e fatores de risco: A importância das habilidades sociais educativas. Em F. J. Penna \& V. G. Haase (Orgs.), Aspectos biopsicossocias da saúde na infância e adolescência. Belo Horizonte: Coopmed.

DiPerna, J. C., Volpe, R. J., \& Elliot, S. N. (1991). A model of academic enablers and elementary reading/language arts achievement. School Psychology Review, 31(3), 298-312.

Errington, E. (2004). The impact of teacher beliefs on flexible learning innovation: some practices and possibilities for academic developers. Innovations in Education and Teaching International, 41(1), 39-47.

Gresham, F. M., Lane, K. L., \& Mac Millan, D. L. (1999). Social and academic profiles of externalizing and internalizing groups: Risk factors for emotional and behavioral disorders. Behavioral Disorders, 24(3), 231-245

Goya, A., Bzuneck, A., \& Guimarães, S. (2008). Crenças de eficácia de professores e motivação de adolescentes para aprender Física. Psicologia Escolar e Educacional, 12(2), 51-66.

Martini, M. L (2003). Variáveis psicológicas de professores e alunos, ações interativas e desempenho acadêmico: investigando possíveis relações. Tese de doutorado, Faculdade de Filosofia Ciências e Letras de Ribeirão Preto, Universidade de São Paulo, Ribeirão Preto, São Paulo.

Martini, M. L., \& Boruchovitch, E. (2004). A teoria da atribuição de causalidade: Contribuições para a formação e atuação de educadores. Campinas, SP: Alínea.

Martini, M. L., \& Del Prette, Z. A. P. (2002). Atribuições de causalidade de professoras do ensino fundamental para o sucesso e o fracasso escolar dos seus alunos. Revista Interação em Psicologia, 6(2), 149-156.
Melchiori, L., Alves, Z., Souza, D., \& Bugliani, M. A. (2007). Família e creche: crenças a respeito de temperamento e desempenho de bebês. Psicologia: Teoria e Pesquisa, 23(3), 245-252.

Neves, M. B. J., \& Almeida, S. F. C. (1996). O fracasso escolar na $5^{\text {a }}$ série, na perspectiva de alunos repetentes, seus pais $e$ professores. Psicologia: teoria e pesquisa, 12, 147-156.

Olaz, F. O. (2009). Contribuições da Teoria Social-Cognitiva de Bandura para o Treinamento de Habilidades Sociais. Em A. Del Prette \& Z. A. P. Del Prette (Eds.), Psicologia das Habilidades sociais: diversidade teórica e suas implicações. Petrópolis, RJ: Vozes.

Pajares, M. F. (1992). Teacher's belief and educational research: Cleaning up a messy construct. Review of Educational Research, 62(3), 307-332

Raudenbush, S. W., Rowan, B., \& Cheong, Y. F. (1993). Higher order instructional goals in secondary school: class, teacher and school influences. American Educational Research Journal, 30(3), 523553.

Raymond, A. M., \& Santos, V. (1995). Preservice elementary teachers and self-reflection: how innovation in Mathematics teacher preparation challenges mathematics beliefs. Journal of Teacher Education, 46(1), 58-70.

Sadalla, A. M. F. A., Saretta, P., \& Escher, C. (2002). Análise das crenças e suas implicações para a educação. Em R. G. Azzi \& A. M. F. A. Sadalla (Eds.), Psicologia e formação docente: desafios e conversas (pp. 93-112). São Paulo: Casa do Psicólogo.

Warfield, J., Wood, T., \& Lehman, J. D. (2005). Autonomy, beliefs and the learning of elementary mathematics teachers. Teaching and Teacher Education, 21(4), 439-459.

Weiner, B. (1985). An attributional theory of achievement, motivation and emotion. Psychological Review, 92(4), 548-573.

Weiner, B. (2006). Social motivation, justice and the moral emotionas. An attributional approach. London: Lawrence Erlbaum.

Zohar, A., Degani, A., \& Vaaknin, E. (2001). Teachers' beliefs about low-achieving students and higher order thinking. Teaching and Teacher Education, 17(4), 469-485.
Recebido em: 04/03/2008

Reformulado em: $23 / 07 / 2009$

Aprovado em: 28/07/2009

\section{Sobre as Autoras}

Mirella Lopez Martini Fernandes Paiva

Acadêmica da Universidade Federal de São Carlos, São Paulo/BR.

Professora Titular do Departamento de Psicologia da Universidade Federal de São Carlos. 